\title{
Congenital Aplasia of the Uterine-Vaginal Segment in Dogs
}

\author{
Bruno Colaço, Maria dos Anjos Pires \\ and Rita Payan-Carreira \\ CECAV, Univ. of Trás-os-Montes and Alto Douro, \\ Portugal
}

\section{Introduction}

Müllerian duct abnormalities consist of a set of structural malformations that include diverse situations of agenesis or aplasia, which may evolve according to three distinct patterns: a failure of the paramesonephric ducts (Müllerian ducts) to develop in the whole or in part (uterus unicornis and segmental aplasia of uterine horn, respectively), the failure of caudal part of the paramesonephric ducts to the fuse and to form one single lumen (leading to situations such as uterus didelphus and the cranial vagina septation) and the failure of the fused caudal paramesonephric ducts to fuse with the urogenital sinus with consequent absence of anatomic continuity between the cranial vagina and the vestibule (originating an imperforate hymen or the vaginal stenosis).

Prevalence of these anomalies ranges from 0.02 to $0.05 \%$ in the canine population (Roberts, 1971; McIntyre et al., 2010). The relative frequency of the different abnormalities varies upon the region and the year of publication (Roberts, 1971; Ortega \& Pacheco, 2007; McIntyre et al., 2010), and the clinical descriptions are insufficient to establish epidemiology of the defects.

In dogs, the uterine and vaginal segments can show developmental abnormalities ranging in severity from hypoplasia to complete agenesis (Romagnoli \& Schlafer, 2006; McIntyre et al., 2010), and the severity of the defect influences the reproductive outcome and the existence of clinical side effects. The mildest form is the vagino-vestibular stricture, where secretions are collected in the cranial vagina and uterus, while in the more extreme form the uterus may be partially or in the whole reduced to a string, fibrous structure.

Although not uncommonly found during elective ovariohysterectomy, often they are detected co-existing with increased dimensions of the uterus and signs of mucometra or pyometra. There is a complete obstruction to fluid drainage from the uterus (as in vaginal or cervical atresia) and the owner may complaints that the female does not evidence the expected estrus vulvar discharge. With time, in obstructive diseases of the uterus or vagina, it is also possible to observe dysuria, cystitis, pyometra and renal failure (Kyles et al, 1996). However, in unicornuate uterus this is seldom the case and often the main complaint is infertility or sterility (Romagnoli \& Schlafer, 2006; McIntyre et al., 2010). The animal may 
have been breed with success previous to the diagnosis, albeit the number of puppies in the litter is usually remarkably small comparing to the normal for the breed (Romagnoli \& Schlafer, 2006; McIntyre et al., 2010). Sporadically, vulvar discharge, excessive vulvar licking and attraction of the male have been described (Kyles et al, 1996; Tsumagari et al., 2001).

The aim of this study was to discuss embryology, the gross anatomic features, clinical signs and implications, and available diagnostic approaches in cases of Müllerian duct anomalies.

\section{Classification}

Non-development or non-fusion (partial or complete) of Müllerian ducts may result in a variety of anomalies ranging from complete agenesis to duplication of female reproductive organs (Moore \& Persaud, 2008).

In different clinical reports, a tendency for the use of different classifications for a common defect was found. Also, it is frequently found similar defects named distinctly for different species, in which develop with different patterns. These are indicative of the necessity of adopting a more uniform nomenclature. In an attempt to clarify the nomenclature used in this review, and to allow the easy identification of underlying major causes for a given defect, table 1 presents the classification for the anatomical congenital defects of the uterinevaginal segment in dogs.

\begin{tabular}{|c|c|c|c|}
\hline Main cause & Malformation & \multicolumn{2}{|c|}{ Classification } \\
\hline \multirow[b]{2}{*}{$\begin{array}{c}\text { Failure in } \\
\text { organogenesis }\end{array}$} & \multirow[b]{2}{*}{$\begin{array}{c}\text { Failure of segments of } \\
\text { Müllerian ducts to develop }\end{array}$} & Complete & Uterus unicornis \\
\hline & & Incomplete & $\begin{array}{l}\text { Segmental aplasia } \\
\text { of the uterus } \\
\text { (uni or bilateral) }\end{array}$ \\
\hline \multirow{4}{*}{$\begin{array}{l}\text { Failure in } \\
\text { fusion }\end{array}$} & \multirow{2}{*}{$\begin{array}{l}\text { Failure of the caudal parts } \\
\text { of the two Müllerian ducts } \\
\text { to fuse appropriately and } \\
\text { develop a single lumen }\end{array}$} & \multicolumn{2}{|c|}{$\begin{array}{l}\text { Segmental aplasia of the body } \\
\text { or the cervix }\end{array}$} \\
\hline & & \multicolumn{2}{|c|}{$\begin{array}{c}\text { Longitudinal septation of the } \\
\text { uterine body* } \\
\text { Uterus didelphus* }\end{array}$} \\
\hline & \multirow{2}{*}{$\begin{array}{l}\text { Failure of caudal ends of } \\
\text { the Müllerian ducts to fuse } \\
\text { with invaginated } \\
\text { urogenital sinus thus } \\
\text { impairing the } \\
\text { establishment of } \\
\text { anatomical continuity }\end{array}$} & \multicolumn{2}{|c|}{$\begin{array}{c}\text { Segmental stenosis or aplasia of } \\
\text { the vagina } \\
\text { (Also named vestibulo-vaginal } \\
\text { constriction) }\end{array}$} \\
\hline & & \multicolumn{2}{|c|}{$\begin{array}{l}\text { Longitudinal septum in the } \\
\text { cranial vagina* } \\
\text { Imperforate hymen* }\end{array}$} \\
\hline
\end{tabular}

* Out of the scope of this review

Table 1. Classification of developmental abnormalities of the uterine-vaginal segment in dogs according to underlying malformations. 
Congenital aplasia of the uterus or vagina may occur in two variants: showing the normal development of muscular and serosal external layers, but without development of the mucosa, originating the atresia of the more internal layers; or may result from failure in development of all the layers in a more or less extended segment, which is reduced to a fibrous cordiform remnant. The former gives origin to a dense fibrous transverse partition in middle to caudal vagina, while in the later the agenesis segment miss from the normal anatomy (Gee et al., 1977; Moore \& Persaud, 2008; McIntyre et al., 2010).

\section{Physiopathology}

Many vertebrates share a common genetic system for embryonic patterning that includes the reproductive tract. To better understand the uterus and vagina congenital anomalies we will first discuss the normal tubular genitalia development.

Normal development of the female reproductive tract involves a series of highly orchestrated, complex interactions that direct differentiation of the Müllerian ducts and urogenital sinus to form the internal female reproductive tract. This dynamic process is completed throughout mechanisms of differentiation, migration, fusion, and canalization. In the indifferent stage both male and female embryos have 2 sets of paired genital ducts (Mcgeady et al., 2006): Wolffian (mesonephric) and the Müllerian (paramesonephric). Differentiation of the Wolffian ducts occurs earlier in the male embryo, and persists after the mesonephros disintegrates (Noden \& de Lahunta, 1985; Moore \& Persaud, 2008). The female differentiation occurs in a later gestational age, and is characterized by regression of the Wolffian ducts due to absence of masculinisation influences from the gonads, and by stabilization of the Müllerian ducts, which is estrogen sensitive in a precise window of time (Moore \& Persaud, 2008). Estrogens block the development of the Müllerian ducts if applied before the differentiation began, or cause hypertrophy of the differentiated portion and prevented further differentiation of the ducts in more caudal regions, when applied afterwards (Dood \& Wibbels, 2008).

The funnel-shaped cranial region of each paramesonephric duct remains open (communicating with the coelomic cavity) and will form the uterine tube. Postnatally the communication persists from the peritoneal cavity to the exterior (exclusively in females). Caudal to this, each duct develops into an uterine horn. The bilateral paramesonephric ducts caudal portion shift medially and fuse into a single tube. The paired Müllerian ducts, initially separated by a septum, fuse and form a single Y-shaped tubular structure, the uterovaginal primordium (UVP). UVP becomes the uterine body, uterine cervix, and the cranial third of the vagina. Uterine morphology varies significantly in mammals, due to different degrees of fusion of the distinct Müllerian ducts (Noden \& de Lahunta, 1985; Moore \& Persaud, 2008).

Normal vaginal development requires the fusion of components that derive from 2 embryologic structures: the mesodermal Müllerian ducts and the endodermal urogenital sinus (UGS). To achieve this fusion the bilateral blind ending paramesonephric ducts enter in contact with UGS. This contact promotes the cellular proliferation of the endoderm from the urogenital sinus and the formation of the vaginal plate. The vagina is derived from both the vaginal plate and the fused ends of paramesonephric ducts (Mcgeady et al., 2006). The cranial one-third comes from fused paramesonephric ducts and the caudal two-thirds 
originate from the vaginal plate. Degeneration of the center of the vaginal plate creates the vaginal lumen. A hymen may persist where the vagina joins urogenital sinus although in most domestic species it tend to disappear before puberty. The urogenital sinus forms the vestibule (Noden \& de Lahunta, 1985; Moore \& Persaud, 2008).

Apart from some remnants of the excretory tubes and a small portion of the mesonephric duct, with varying importance according to the species, all the female mesonephric derivates atrophies (Moore \& Persaud, 2008).

The cause and heritability of congenital abnormalities in dogs remain undetermined (McIntyre et al., 2010). With exception for the situations accompanying intersex conditions, the karyotype is normal. We are unaware if the condition develops in consequence of genetic, endocrine, or environmental influences. Neither it is known if it might be associated to failure of the gonad or the mesonephros development (which absence may co-exist with the uterus unicornis), to failure in local gene expression or, in the case of a segmental aplasia, if it might be determined by disruption of the blood supply to the affected segment (Ribeiro et al., 2009; McIntyre et al., 2010).

A unilateral uterine aplasia (also termed unicornuate uterus) develops when one paramesonephric duct fails to develop; this results in a uterus with one uterine horn (Moore \& Persaud, 2008). The kidney and the paramesonephric ducts have the same embryologic origin therefore this anomaly is usually associated with ipsilateral kidney absence (Chang et al., 2008). Unilateral uterine aplasia has been reported in dogs and cats (Schulman \& Bolton, 1997; Pinto Filho et al., 2001; Güvenç et al., 2006). However, the ovary is of a separate embryological origin and is usually present (Moore \& Persaud, 2008; Thode \& Johnston, 2009).

Development defects of the Müllerian duct system may cause segmental aplasia in several portions of the Müllerian duct system. Partial or complete fusion or occlusion of one uterine horn, of the body of the uterus, or of the most caudal segments, such as the cervix and cranial vagina, may cause fluid accumulation cranially to the occlusion (McEntee, 1990; Oh et al., 2005; Romagnoli \& Schlafer, 2006; Almeida et al., 2010; McIntyre et al., 2010). Failure of canalization of the vaginal plate results in atresia (blockage) of the vagina, originating a transverse vaginal stenosis or a segmental aplasia, which is found between the middle and the caudal third of the vagina (Schlafer \& Miller, 2007). Isolated vaginal atresia is an extremely rare finding.

Given the many variables that are involved in the female genital tract differentiation and growth, the pathogenesis for each anomaly may be multifactorial and hence of difficult identification (McIntyre et al., 2010).

\section{Gross morphology}

The gross morphological signs vary according to the defect and also the co-existence of secondary diseases or other concomitant uterine or vaginal disease.

\subsection{Unilateral uterine aplasia (Unicornuate uterus)}

In unicornuate uterus situations, aplasia of one uterine horn is the major finding, as it is reduced to a fibrous threadlike structure (Figure 1A and 1B), composed of fibrous tissue 
with some muscle strands (McIntyre et al., 2010) that frequently fail to present a lumen. As the contralateral uterine horn and the other genital segments retain patency, fluid accumulation does not occur unless the female develop cystic endometrial hyperplasia $(\mathrm{CEH})$ / pyometra or other situations of segmental aplasia in the contralateral uterine horn are present (Figure 1A). The non-patent uterine horn may induce fluid accumulation in the oviducts that distend (Figure 1C).

Due to a common embryologic origin, this malformation might co-exist with ipsilateral tubal and renal agenesis (Chang et al., 2008). Although this situation is described with more frequency in cats than in dogs, on its survey McIntyre et al. (2010) found a relative lower frequency of $28 \%$ in cats than $45.5 \%$ in dogs. Co-existence of renal agenesis appears also on older reports on uterus unicornis in female beagles in research colonies (Höfliger, 1971, cited by McEntee, 1990). As those animals were euthanized after the end of the experiments (they integrated the control groups), at young ages, clinical signs were absent. Often the abnormality is detected only at necropsy or surprises the surgeon during the surgery. In contrast, due to a different embryologic origin, most frequently both ovaries are found (Romagnoli \& Schlafer, 2006; McIntyre et al., 2010). Other congenital defects besides kidney agenesis were found in animals bearing unicornuate uterus: ectopic contralateral ureter, absent ipsilateral suspensory ligament and umbilical hernia (McIntyre et al., 2010).

Acquired diseases found in described conditions of unicornuate uterus include $\mathrm{CEH}$ of the contralateral uterine horn and polycystic ovaries. According to the descriptions, the later could correspond to cystic proliferation of the rete or the cranial uterine tube (Güvenc et al., 2006).

\subsection{Segmental aplasia of the uterus}

In cases of segmental aplasia, whether its location may be at the uterine horns, body or cervix, frequently the anomalies are grossly visible as missing segments or strictures that interrupt the normal anatomy of the uterine-vaginal segment, and that correspond to failure of the development of all the layers of that segment, which are often reduced to a streak cord-like rudiment. However, in few situations the external layers of the Müllerian duct derivates (serosal and muscle layers) are properly differentiated, but the inner layers (mucosal and sub-mucosal layers) do not differentiate (Moore \& Persaud, 2008). This is more often found in the vagina than the uterus. In practical terms, the potential deleterious effects over the reproductive potential and the occurrence of secondary diseases are similar in the two situations.

As the situation usually remains undiagnosed in young animals that maintain regular reproductive activity, the normally developed portion cranial to the atresia is distended due to fluid accumulation (Figure 1D to $1 \mathrm{H}$ ). Distension of the uterine tube (Figure 1F) is possible (McIntyre et al., 2010). Primary lesions at the endometrium are rarely reported, but CEH may develop in older animals. However, due to excessive mucous fluid pressure of the ongoing mucometra, with time reduction in the thickness of the uterine walls and compression and attenuation of the endometrial glands is commonly found (McIntyre et al., 2010).

Segmental aplasia of the uterine horns may develop at any point of the structure (Figure 1A, 1C and 1G) (Schlafer \& Miller, 2007; McIntyre et al., 2010), with segmental agenesis being irregularly distributed for different segments of the uterine horns. 

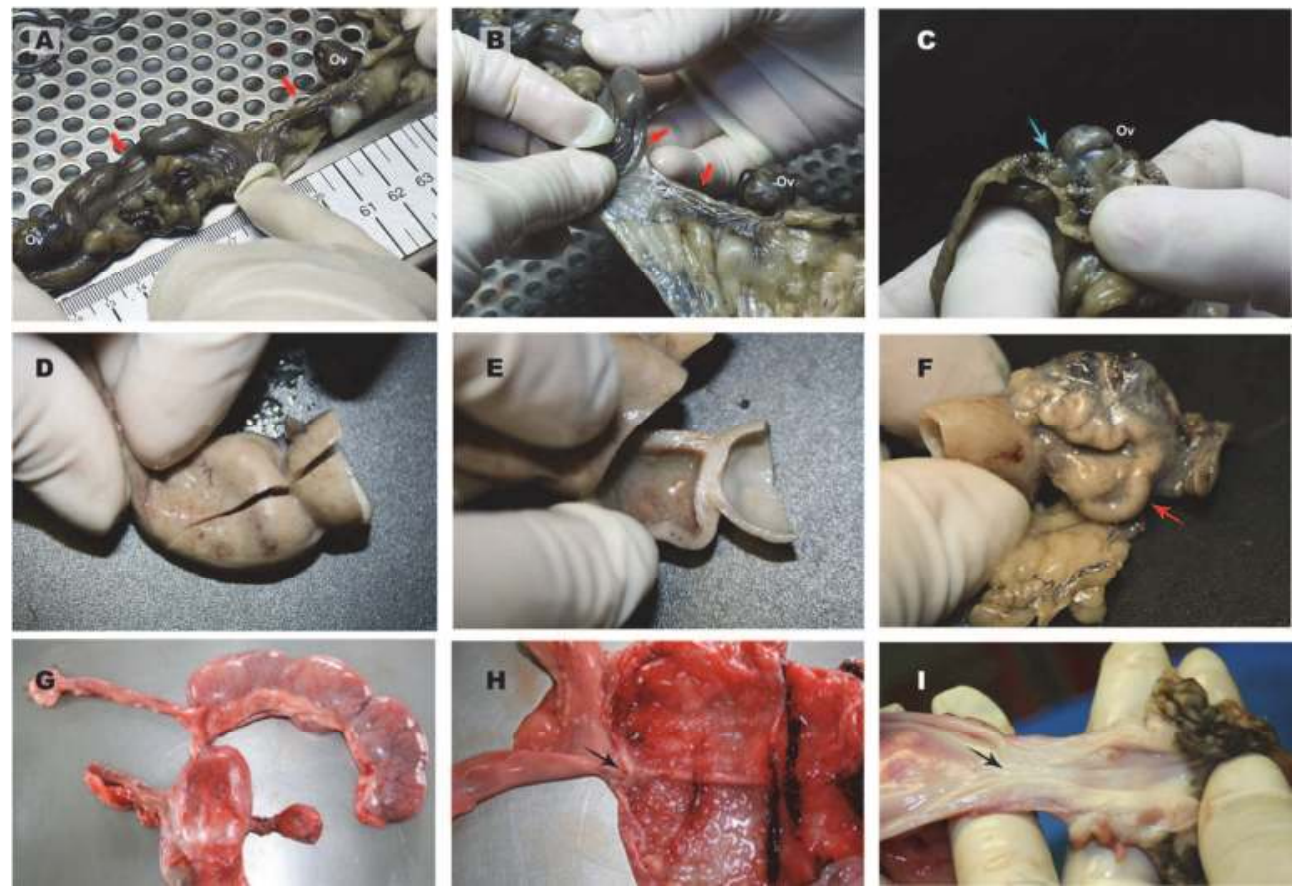

Fig. 1. Canine congenital aplasia of the uterine-vaginal segment: A: The external morphological evaluation showed the complete agenesis of the right uterine horn (unicornuate uterus) co-existing with segmental aplasia of the contralateral uterine horn. Both ovaries $(\mathrm{Ov})$ were present. Arrows indicate areas of agenesis. B: Closer inspection showed that the caudal segment of the left uterine horn is patent, while the right uterine horn is reduced to a threadlike structure parallel to the uterine vessels. The ipsilateral ovary (Ov) was present, within the ovarian bursa. Arrows indicate areas of agenesis. C: Dilatation of the uterine tube (cyan arrow) ipsilateral to the non-developed uterine horn. D: Externally, segmental aplasia of the uterine horn may appear as a marked constriction of the organ. $\mathrm{E}$ : When opened, those areas showed the absence of fusion between adjacent segments, which fail to communicate. Outside undeveloped areas the uterus maintain its normal morphology. F: The ipsilateral uterine tube is distended (arrow), due to fluid pressure. G: Segmental aplasia at the basis of the right uterine horn in a 15 years-old bitch (distension of the vagina was due to a fibroma). $\mathbf{H}$ : The arrow points to the area of aplasia. Long-term effects of the secondary fluid accumulation induced a reduction in the thickness of the walls. I: Segmental stenosis of the vagina: the arrow points to the obstruction.

In animals with segmental aplasia of the uterine body or cervix, as communication between the two uterine horns is possible, equivalent and bilateral uterine horn distension is found (McEntee, 1990; McIntyre et al., 2010). Undeveloped segments are usually reduced to cordlike remnants. In cases of cervical aplasia, the uterine body ends blindly in a pouch, a membranous tissue separating the uterus from the vagina (McEntee, 1990). 


\subsection{Segmental stenosis of the vagina}

Vaginal stenosis has been described as occurring as a complete misdevelopment of all the layers of the vagina, which may be reduced to an atretic segment with variable importance (Figure 1I) (Gee et al., 1977; Viehoff \& Sjollema, 2003; Romagnoli \& Schlafer, 2006) or as originating from the absence of internal canalization with normal developmental of the external layers (Wadsword et al., 1978). The existence of a vaginal cyst cranial to the occlusion has been referred, which has been attributed to incomplete canalization of the embryonic derivate, hence allowing the development of intermediary segments between missing portions (Gee et al., 1977; McEntee, 1990). The undeveloped segment is usually located near the vestibulo-vaginal junction (Gee et al., 1977; Kyles et al., 1996; Viehoff \& Sjollema, 2003) and on gross evaluation morphology of the anatomical region may share some resemblances with imperforate hymen. The missing segment may present variable extension.

Similarly to the findings for segmental aplasia of the uterine body or cervix, fluid accumulation above the agenesis induces uterine dilatation, but contrasting to those malformations, fluid accumulation also occurs on the remainder cranial segment of the vagina.

Vaginal cysts near the point of stenosis have been described (Gee et al., 1977). It has been proposed to correspond to incomplete canalization of atrectic segments (Gee et al., 1977; McIntyre et al., 2010). Impairment of fluid drainage induces fluid accumulation above the obstruction and consequently distension of cranial reproductive tract (Gee et al., 1977; Viehoff \& Sjollema, 2003; McIntyre et al., 2010). In contrast to the observed in the previously described situations, fluid accumulates within the uterus (mucometra) and the vagina (hydrocolpos). As vaginal walls are thinner than those of the uterus they distend more easily, thus reaching higher increases in size comparatively to the uterine distension. These morphological features are not exclusive for the segmental stenosis of the vagina. Imperforate hymen shares similar gross appearance (Tsumagari et al., 2001; Schlafer \& Miller, 2007), except that the transverse partition is thinner in the later than in the segmental stenosis.

\section{Clinical signs}

Congenital abnormalities of the uterine-vaginal segment in dogs are seldom detected before puberty. Furthermore, in a large number of cases remains unnoticed until secondary diseases develop or until unsuccessful attempts for breeding the female alert the owner to the need for a detailed reproductive examination of the infertile animal. Early diagnosis of those conditions would avoid owners to maintain a bitch with severe congenital diseases in the reproductive stock. Also, the correct identification of the disease and evaluation of the importance of the defect would allow proper counselling on the therapeutic approach and establish a prognosis for a specific condition. Further, it will permit to anticipate the occurrence of secondary, associated diseases that can develop if the primary condition is not treated and that may threaten the health of the female.

\subsection{Unilateral uterine aplasia (Unicornuate uterus)}

The occurrence of unicornuate uterus is rare, but results from different surveys report different relative frequencies. Ortega and Pacheco (2007) in tropical regions reported a 
frequency of $0.3 \%$ (1:300 lesions of the genital tract) whilst McIntyre et al. (2010) found $73.3 \%$ (11:15 of the canine uterus disorders found). It is possible that the genetics of the population surveyed may have influenced, in particular the proportion of purebred and crossbred females, as well as the analysed segments of the genital tract.

Most often, in cases of complete aplasia of one uterine horn the female usually presents regular oestrous cycles (Pinto Filho et al., 2001; Güvenç et al., 2006; Almeida et al., 2010), and often the animal history include the reference to successful pregnancy and parturition, although with a smaller litter size than the expected for the breed (Romagnoli \&Schlafer, 2006; McIntyre et al., 2010). It is also possible the reference to the existence of a reduced intensity in the vaginal discharge accompanying estrus, but this is not usually reported in any of the cited literature. Individuals with agenesis of one uterine horn may also have an increased incidence of premature delivery (Seyrek-Intas et al., 2004). Usually, in young dogs clinical signs other than sub-fertility are absent, the condition being detected at the necropsy or during a convenience OVH. That was the case in one of the situations we had: a small Poodle dog of 2 years of age with regular estrous cycles that was submitted to convenience $\mathrm{OVH}$. The uterine defect was found during surgical procedure, in the absence of symptoms. The owner only reported the existence of a vulvar discharge of decreased intensity when compared to that of her mother. Pinto Filho et al. (2001) described a similar situation in a Poodle female with 2 years of age, without clinical signs, that was submitted to elective surgery.

However, older animals may present signs of disease located in the uterus (such as CEH or pyometra), as in the report by Güvenç et al. (2006). Nevertheless, one should be aware that those are generally of independent occurrence, as $\mathrm{CEH} /$ pyometra frequently develops in the uterus of old intact females. Güvenç et al. (2006), report in a 12 years-old Cocker Spaniel, the existence of a serous sanguineous vulvar discharge persisting for 5 weeks, in the absence of other clinical symptoms, which was the main reason for the consultation. However, at surgery polycystic ovaries were found. Thus it cannot be excluded that the discharge might rather be associated to the ovarian disease than to the uterine defect.

The bilateral agenesis of the uterine horns is extremely rare in dogs (Schlafer and Miller, 2007).

\subsection{Segmental aplasia of the uterine(s) horn(s)}

Partial or complete agenesis of a more or less extended segment of the uterine horns (segmental aplasia) is relatively common in dogs; in the survey by McIntyre and colleagues (2010) it accounted for $20 \%$ of the congenital anomalies of the uterus. Most frequently it is an unilateral condition, but some descriptions referred to bilateral situations (McIntyre et al., 2010), in which segmental agenesis was irregularly distributed for different segments of both uterine horns. This was also observed in one of our cases, in middle aged Poodle crossbred female. The agenesic segment may develop at any point of the uterine horns (McEntee, 1990; Romagnoli \& Schlafer, 2006; McIntyre et al., 2010). The moment for the onset of clinical signs detection partly depends on its location and extension. Whenever it exists an obstruction to the normal outflow of the endometrial secretions, accumulation of a sterile fluid with distension of uterine walls (Figure $1 \mathrm{D}$ and $1 \mathrm{G}$ ) is the main outcome 
(McEntee, 1990; Romagnoli \& Schlafer, 2006; McIntyre et al., 2010). As consequence of the excessive pressure, the female may present mild signs of uterine disease (such as abdominal distension, tenesmus or dysuria) albeit usually haematological exams and clinical biochemistry are within or close to normal values. In one of the situations we had, in a Rottweiler female with 5 years of age, signs of cystic endometrial hyperplasia co-existed in the remainder segments of the uterus. Though these are unrelated conditions, as already mentioned, the uterine segment retaining patency may develop a pyometra, which may completely change the clinical scenario for the patient. In this particular case, the segmental aplasia was diagnosed after surgery.

Whenever a segmental aplasia of the cranial part of the uterine horn is found, it may also be found a distended uterine tube. This situation has been described for cats and rabbits (Thode \& Johnston, 2009), but was not mentioned in the reports on dogs we have accessed. However, non-mention may also mean that the structure was not evaluated. In our Rottweiler case, gross evaluation of the excised genitalia fail to evidence distension of the uterine tubes; however, a muco-purulent fluid was found in the ovarian bursa suggesting the flow of the uterine content through the oviducts. Also in two other situations, oviductal dilatation was found during histopathological evaluation (Figures $1 \mathrm{C}$ and $1 \mathrm{~F}$ ).

\subsection{Segmental aplasia of the uterine body and cervix}

Although rare, sporadic reports on the agenesis of the uterine body have been published for the dog (Oh et al., 2005; McIntyre et al., 2010). The aplasia of the canine cervix was seldom described (McEntee, 1990).

Both conditions allow communication between the two uterine horns and completely impair fluid drainage from the uterus. Consequently, one of the main symptoms may be the existence of estrus signs (swollen vulva and male attraction) in the absence of the characteristic vulvar discharge (non-technically described as "dry" estrus). Furthermore, as none of the endometrial secretions drain from the genital tract, as the female retains her cyclicity, signs secondary to excessive fluid accumulation may develop earlier when compared to segmental aplasia, and the abdominal distension is usually noticed earlier. Uterine distension, in this situation, is bilateral and symmetric (Oh et al., 2005; McIntyre et al., 2010).

\subsection{Segmental stenosis of the vagina}

Animals presenting segmental stenosis of the vagina, as do those showing aplasia of the uterus or of the cervix, do not present the typical estrus vulvar discharge, despite the existence of regular cyclicity (Viehoff \& Sjollema, 2003). However, chronicle, intermittent vaginitis is the most frequently described clinical symptom and the common to all the reports on segmental stenosis of the vagina (Gee et al., 1977; Kyles et al., 1996; Viehoff \& Sjollema, 2003). It usually induces a more or less intense vulvar discharge, excessive licking of the vagina and dysuria. Recurrent cystitis was also found in such conditions (Kyles et al., 1996). Due to common symptoms, differential diagnosis between segmental stenosis of the vagina (Viehoff \& Sjollema, 2003) and the imperforate hymen (Tsumagari et al., 2001) on the basis of the symptoms is difficult. 


\section{Diagnosis}

Diagnosis of aplasia of the uterine-vaginal segment in dog before puberty or in young nonbreeding dogs is seldom achieved, as clinical evidences are absent. Also, since the ovaries are present in congenital aplasia of the uterine-vaginal segment, normal cyclicity after puberty does not allow suspecting the existence of a defect.

Thus congenital aplasia of the uterine-vaginal is frequently asymptomatic and often missed during routine gynaecological examination, unless side effects associated to failure of genital patency develop in more severe or more prolonged situations. Further, due to unspecific and limited clinical symptoms described, congenital aplasia often requires more than one diagnostic approach to assure success.

Clinical signs or mild illness appears in older bitches, usually associated with fluid retention within the uterus or with other age-related diseases of the genital tract. The later is not taken into consideration herein when describing the diagnostic approach.

In unilateral uterine aplasia, few clinical signs develop even in older animals that may be related to the defect. The owner may complain on the female low prolificacy (Romagnoli \& Schlafer, 2006; McIntyre et al., 2010) or on the tendency of recurrent abortion in the absence of microbiological or parasitic agents. Vaginoscopy or digital manipulation fails to evidence the primary defect. On ultrasound, the inability to find one uterine horn or the finding of a fibrous threadlike structure on its normal location are the expected findings. Both ovaries are found. Simple X-rays are not useful for diagnosis unless hysterosalpingography (a contrast X-ray) is performed. This would reveal that diffusion of the contrast is limited to one of the uterine horns, particular when using dorso-ventral projections.

A similar situation is found in the segmental aplasia of the uterine horns. Unless fluid accumulation in the uterine segment above the atresia becomes important and may be suspected during routine abdominal palpation or ultrasound, the defect remains undetectable in routine consultations. Complains on the female sub-fertility in the presence of regular estrous cycles may exist. The vaginoscopy and digital manipulation are not useful to evidence the primary defect. On ultrasound, segments of the uterus may show uterine distension, uterine walls of variable thickness and areas where the uterus is absent or reduced to a cord-like fibrous structure. However, often the image resembles that of a mucometra/pyometra, except that uterine distension may be limited to one portion of the uterus. On simple X-ray it may be observed dense, non-continuous masses in the normal location of the uterus, frequently in one side of the body, while the remainder parts of the genital tract are not visible. Comparison of these X-rays with those obtained by hysterosalpingography will allow to visualise the occlusion and the existence of a dense pouch cranially.

In the segmental aplasia of the uterine body and cervix, the most important symptom for diagnosis is the absence of the typical estrus vulvar discharge in a regularly cycling female (Oh et al., 2005; McIntyre et al., 2010). With time, also abdominal distension associated to uterine distension due to mucometra is found. During abdominal palpation, a uterus increased in size is detected. The vaginoscopy and digital manipulation fail to evidence the primary defect. On ultrasound, bilateral distension of the uterus, thin uterine walls and anechoic or hypoechoic uterine content are commonly found. The distension of the body of 
the uterus may be found when cervical agenesis exists. The thickness of the uterine walls is equivalent in the uterine horns and body. Radiographic signs are similar to those of mucometra or pyometra. Hysterosalpingography allows to identify the local of occlusion.

In case of segmental stenosis of the vagina, the major symptom is also the absence of the estrus vulvar discharge in a regularly cycling female. However, a large number of females also present clinical history of intermittent, chronic vaginitis or of recurrent, chronic lower urinary tract infection (Kyles et al, 1996; McIntyre et al., 2010), which have not being reported in the aplasia of the uterine body or cervix. Abdominal palpation shows increased size of the uterus that prolongs caudally into the pelvic brim (cranial segment of the vagina). As the vagina dilates more than the uterine body, it can appear as being more ballooned. Also transrectal digital palpation shows the distension of the vagina, that appears as a balloon at the entrance of the pelvic vault. Digital manipulation of the vagina or vaginoscopy usually allows detecting the defect (Kyles et al., 1996; Viehoff \& Sjollema, 2003). On the ultrasound bilateral distension of the uterus is observed, as in the segmental aplasia of the uterine body or cervix, which is prolonged beneath the urinary bladder into the pelvic brim. The bladder may be dislocated from its normal position. Ultrasound scans allow to distinguish between the uterine and the vaginal segment, the latter having thinner walls and usually increased dilatation. On simple X-rays cranioventral displacement of the bladder and increased dimensions of the uterus, extending into the vaginal position, are observed. Hysterosalpingography allows the localization of the occlusion.

For the defects originating in the cervix or the vagina, endoscopic visualization of the vaginal cavity and of the cervical morphology may be useful in diagnosis. Furthermore, three-dimension ultrasonography and the magnetic resonance imaging may give useful information on the development of the genital structures even when secondary diseases are absent. However, these techniques are not easy to develop in the current veterinary clinics.

On table 2 we condensed the most relevant information to reach diagnosis.

\section{Therapeutic management}

To propose a treatment for any of the different conditions of congenital aplasia of the uterine-vaginal segment in dogs is a difficult task. For unicornuate uterus no direct negative effects arise from the defect by itself, and there are no additional risks for the health of the bitch other than those associated with age in intact females.

For the different segmental aplasia of the uterus (concerning the uterine horns, body or cervix) no effective therapeutic approach is available, and ovariohysterectomy remains the solution to avoid future health problems for the bitch, associated to fluid retention in the uterus with posterior inflammation.

In the case of segmental stenosis of the vagina, the treatment of the defect may be attempt to maintain the breeding status of the bitch, unless a large segment of the vagina is missing, which could bring potential problems during mating and delivery (Viehoff \& Sjollema, 2003). Anastomosis of the vagina and vestibule may be attempt through episiotomy (Kyles et al., 1996; Viehoff \& Sjollema, 2003). The success of the technique has yet to be ascertained in more severe cases of agenesis of the vaginal segment. 


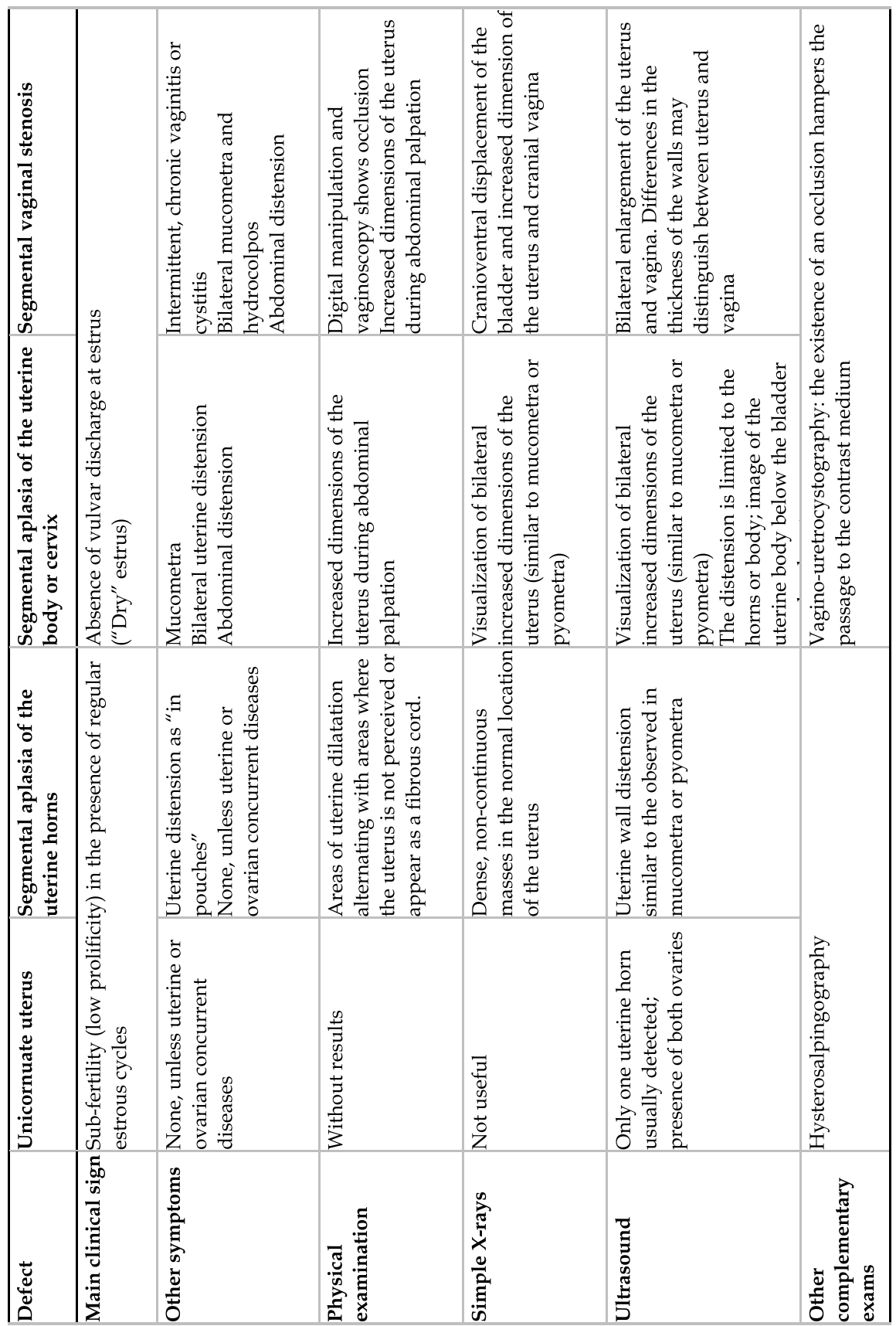

Table 2. Resumed guidelines for reach a diagnosis in congenital segmental agenesis of the uterine-vaginal segment in dogs. 


\section{Conclusions}

Congenital agenesis of the uterine-vaginal segment in dogs consists of a wide range of defects that usually progress undetected until development of associated side effects of the defect, such as mucometra and hydrocolpos, or recurrent cystitis or chronic vaginitis. Surgical correction of the congenital abnormality is seldom possible. Thus it is important to be aware of the most adequate approaches for its early diagnosis, allowing to exclude the affected animals from the reproductive stock.

\section{Aknowledgements}

This work was supported by the project from CECAV/UTAD with the reference PEstOE/AGR/UI0772/2011, by the Portuguese Science and Technology Foundation.

\section{References}

Almeida, M.V.; Rezende, E.P.; Lamounier, A.R.; Rachid, M.A.; Nascimento, E.F.; Santos, R.L. \& Valle, G.R. (2010) Aplasia segmentar de corpo uterino em cadela sem raça definida: relato de caso. Arq. Bras. Med. Vet. Zootec., Vol. 62, No4, pp.794-800.

Chang, J.; Jung, J.H.; Yoon, J.; Choi, M.C.; Park, J.H.; Seo, K.M. \& Jeong, S.M. (2008) Segmental aplasia of the uterine horn with ipsilateral renal agenesis in a cat. J. Vet. Med. Sci., Vol. 70, pp. 641-643.

Dood, K.L. \& Wibbels, T. (2008) Estrogen inhibits caudal progression but stimulates proliferation of developing müllerian ducts in a turtle with temperature-dependent sex determination. Comp. Biochem. Physiol., Vol.150, No3,pp. 315-9

Gee, B.R.; Pharr, J.W. \& Fuerneaux R.W. (1977) Segmental aplasia of Müllerian duct system in a dog. Can. Vet. J., Vol. 18, pp. 281-286.

Güvenç, K.; Toydemir, F.S.; Sontaş, H.B. \& Şenünver, A. (2006) A Cocker Spaniel bitch with uterus unicornis (unilateral cornual agenesis). J. Fac. Vet. Med. Istanbul Univ., Vol. $32, \mathrm{n}^{\circ} 3,69-73$.

Kyles, A.E.; Vaden,S.; Hardie, EM \& Stone, E.A. (1996) Vestibulo-vaginal stenosis in dogs:18 cases[1987-1995]. J. Am.Vet.Med. Assoc., Vol. 209, pp. 1889-93.

McEntee K. (1990) Reproductive pathology of domestic mammals, $1^{\text {st }}$ ed. Academic Press, San Diego, CA.

Mcgeady, T.A.; Quinn, P.J.; Fitzpatrick, E.S. \& Ryan, M.T. (2006) Veterinary embryology. Blackwell Publishing, Oxford.

McIntyre, R.L.; Levy, J.K.; Roberts, J.F. \& Reep, R.L. (2010) Developmental uterine anomalies in cats and dogs undergoing elective ovariohysterectomy. J. Am. Vet. Med. Assoc.,Vol. 237, pp. 542-546

Moore, K.L. \& Persaud, T.V. (2008) The urogenital system. In: The developing human clinically oriented embryology. $8^{\text {th }}$ ed. Saunders\&Elsevier, Philadelphia, PA., pp. 243-269

Noden D.M. \& de Lahunta A. (1985) The embryology of domestic animals,1st ed. Williams \&Wilkins, Baltimore, MD.

Oh, K.S.; Son, C.H.; Kim, B.S.; Hwang, S.S.; Kim, Y.J.; Park, S.J.; Jeong, J.H.; Jeong, C.; Park, S.H. \& Cho, K.O. (2005) Segmental aplasia of uterine body in an adult mixed breed dog. J. Vet. Diag. Invest., Vol. 17, pp. 490-492 
Ortega-Pacheco, A.; Segura-Correa, J.C.; Jimenez-Coello, M. \& Forsberg, C.L.(2007) Reproductive patterns and reproductive pathologies of stray bitches in the tropics. Theriogenology, Vol. 67, pp. 382-390.

Pinto Filho, S.T.; Cunha, O.; Raiser, A.G.; Barbosa, G.S.;Portella, L.C. \& Irigoyen, L.F. (2001) Unilateral uterine agenesis in a bitch- A case report. Arq. Ciên. Vet. Zool. UNIPAR, Vol. 4, No1, pp.77-79.

Ribeiro, S.C.; Tormena, R.A.; Peterson, T.V.; Gonzáles, M.O.; Serrano, P.G.; Almeida, J.A. \& Baracat, E.C. (2009) Müllerian duct anomalies:review of current management. Sao Paulo Med. J., Vol. 127, n'2, pp. 92-6

Roberts, S.J. (1971). Veterinary Obstetrics and Genital Diseases. Woodstock, VT: Self published; First edition.

Romagnoli, S. \& Schlafer, D.H. (2006) Disorders of sexual differentiation in puppies and kittens: a diagnostic and clinical approach. Vet. Clin. North Am. Small Anim. Pract., Vol. 36, pp. 573-606.

Schlafer, D.H. \& Miller, R.B. (2007) Female genital system. In: MAXIE, M.G. (Ed). Jubb, Kennedy, and Palmer's Pathology of Domestic Animals. $4^{\text {th }}$ ed. Philadelphia: Elsevier Saunders:429-564.

Schulman, M.L. \& Bolton, L.A. (1997) Uterine horn aplasia with complications in two mixedbreed bitches. J.S. Afr. Vet. Assoc., Vol. 68, pp.150-153

Seyrek-Intaş, K.; Wehrend, A.; Nak, Y.; Tek, H.B.; Yilmazbaş, G.; Gökhan, T. \& Bostedt, H. (2004) Unilateral hysterectomy (cornuectomy) in the bitch and its effect on subsequent fertility. Theriogenology, Vol. 61, pp.1713-1717

Thode,H.P. \& Johnston, M.S. (2009) Probable congenital uterine developmental abnormalities in two domestic rabbits. Vet. Rec., Vol. 164, pp.242-244

Tsumagari, S.; Takagi, S.; Takeishi, M. \& Memon, M.A. (2001) A case of a bitch with imperforate hymen and hydrocolpos. J.Vet. Med.Sci. Vol. 63, No4, pp. 475-477.

Viehoff, F.W \& Sjollema, B.E. (2003) Hydrocolpus in dogs: surgical treatment in two cases. J. Small Anim. Pract. Vol. 44, pp. 404-407

Wadsworth, P.F.; Hall, J.C. \& Prentice, D.E. (1978) Segmental aplasia of the vagina in the beagle bitch. Lab. Anim., Vol. 12, pp.165-166. 


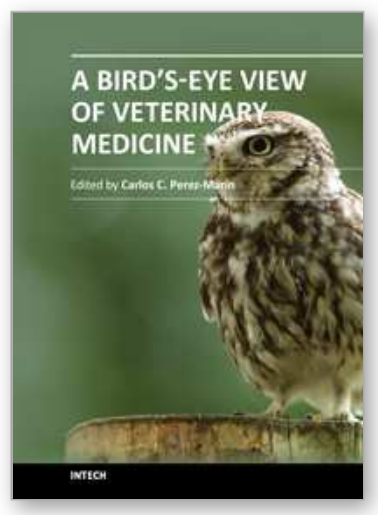

\author{
A Bird's-Eye View of Veterinary Medicine \\ Edited by Dr. Carlos C. Perez-Marin
}

ISBN 978-953-51-0031-7

Hard cover, 626 pages

Publisher InTech

Published online 22, February, 2012

Published in print edition February, 2012

Veterinary medicine is advancing at a very rapid pace, particularly given the breadth of the discipline. This book examines new developments covering a wide range of issues from health and welfare in livestock, pets, and wild animals to public health supervision and biomedical research. As well as containing reviews offering fresh insight into specific issues, this book includes a selection of scientific articles which help to chart the advance of this science. The book is divided into several sections. The opening chapters cover the veterinary profession and veterinary science in general, while later chapters look at specific aspects of applied veterinary medicine in pets and in livestock. Finally, research papers are grouped by specialisms with a view to exploring progress in areas such as organ transplantation, therapeutic use of natural substances, and the use of new diagnostic techniques for disease control. This book was produced during World Veterinary Year 2011, which marked the 250th anniversary of the veterinary profession. It provides a fittingly concise and enjoyable overview of the whole science of veterinary medicine.

\title{
How to reference
}

In order to correctly reference this scholarly work, feel free to copy and paste the following:

Bruno Colaço, Maria dos Anjos Pires and Rita Payan-Carreira (2012). Congenital Aplasia of the UterineVaginal Segment in Dogs, A Bird's-Eye View of Veterinary Medicine, Dr. Carlos C. Perez-Marin (Ed.), ISBN: 978-953-51-0031-7, InTech, Available from: http://www.intechopen.com/books/a-bird-s-eye-view-of-veterinarymedicine/congenital-atresia-of-the-uterine-vaginal-segment-in-dogs

\section{INTECH}

open science | open minds

\section{InTech Europe}

University Campus STeP Ri

Slavka Krautzeka 83/A

51000 Rijeka, Croatia

Phone: +385 (51) 770447

Fax: +385 (51) 686166

www.intechopen.com

\section{InTech China}

Unit 405, Office Block, Hotel Equatorial Shanghai

No.65, Yan An Road (West), Shanghai, 200040, China

中国上海市延安西路65号上海国际贵都大饭店办公楼 405 单元

Phone: +86-21-62489820

Fax: $+86-21-62489821$ 
(C) 2012 The Author(s). Licensee IntechOpen. This is an open access article distributed under the terms of the Creative Commons Attribution 3.0 License, which permits unrestricted use, distribution, and reproduction in any medium, provided the original work is properly cited. 